\title{
Convolutional neural network (CNN) to determine the character of wayang kulit
} \author{
$\mathrm{Ghosh}^{\mathrm{c}, 4}$ \\ ${ }^{a}$ Universitas Negeri Malang, Jl. Semarang No.5, Malang 65145, Indonesia; \\ ${ }^{\mathrm{b}}$ ASCEE Indonesia Section, Indonesia \\ ${ }^{\mathrm{c}}$ ASCEE Australia Section, Australia \\ ${ }^{1}$ aji.prasetya.ft@um.ac.id, ${ }^{2}$ wahyuarbianda@gmail.com, ${ }^{3}$ aniknur.ft@um.ac.id, ${ }^{4}$ anusua @ ascee.org \\ * corresponding author
}

Aji Prasetya Wibawa ${ }^{\mathrm{a}, \mathrm{b}, 1^{*}}$, Wahyu Arbianda Yudha Pratama ${ }^{\mathrm{a}, 2}$., Anik Nur Handayani ${ }^{\mathrm{a}, 3}$, Anusua

INFO ARTIKEL

\section{Article history}

Received 2021-06-12

Revised 2021-06-19

Accepted 2021-06-28

\section{Keywords}

Image Classification

Wayang Kulit

Character

Object Detection

Convolutional Neural Network (CNN)

\section{ABSTRACT}

Indonesia is a country with diverse cultures. One of which is Wayang Kulit, which has been recognized by UNESCO. Wayang kulit has a variety of names and personalities. However, most younger generations are not familiar with the characters of these shadow puppets. With today's rapid technological advancements, people could use this technology to detect objects using cameras. Convolutional Neural Network (CNN) is one method that can be used. CNN is a learning process included in the Deep Learning section and is used to find the best representation. The CNN is commonly used for object detection, would be used to classify good and evil characters. The data used consists of 100 black and white puppet images that were downloaded one at a time. The data was obtained through a training process that uses the CNN method and Google Colab to help speed up the training process. After that, a new model is created to test the puppet images. The result obtained a 92 percent accuracy rate, which means that CNN can differentiate the Wayang Kulit character.

This is an open access article under the CC-BY-SA license

\section{Introduction}

Wayang Kulit is a traditional Indonesian art genre that has been designated as a "Masterpiece of Oral Intangible Heritage of Humanity" by UNESCO [1], [2]. Wayang Kulit has a variety of names and characters. Wayang's character demonstrates each character's personality, self-identity, image, character, and qualities [3], [4]. In general, it can be used as a symbol or example of an individual's character. Wayang Kulit characters can be divided into two categories: good (protagonist) and bad (antagonist). Most teenagers nowadays are not familiar with the Wayang Kulit characters. This is due to a decrease in teenagers' interest in traditional Wayang performances, lack of exposure to literature reading related to Wayang Kulit, and a lack of exposure of subject related to Wayang in schools. To spark the interest of the younger generation in Wayang, a range of possible solutions have been created, including establishing a Wayang puppeteer studio [5], craftsman center [6], [7], and performing Wayang on stage in various locations. Another worthwhile effort is producing Wayang in a more modern form such as wayang hip hop [8], comics [9], games [10], [11], and animations [12]-[14].

A technological breakthrough is needed to make the Wayang Kulit character more recognizable among the numerous existing solutions. A subset of artificial intelligence known as computer vision may be used as one potential approach. This branch investigates how a machine can identify an object while it is being observed. Convolutional Neural Network $(\mathrm{CNN})$ is among the methods for detecting objects. Various studies on CNN, such as one conducted by [15] using CNN to detect faces using 
Tensorflow and Keras, provide a 95 percent accuracy rate. A similar research project achieved an accuracy of 98.14 percent. Another study has $98.3 \%$ of accuracy [16]. Furthermore, [17] recognize a face with a 92.5 percent accuracy rating. CNN appears to be accurate for facial recognition. Combination with other approaches such as SVM [18], GLCM [19] is also promising to improve the $\mathrm{CNN}$ performance. Inspired by the success of $\mathrm{CNN}$ for face recognition, this research will use CNN to classify the characters of Wayang Kulit. The findings of this research could be used as a starting point for another classification based on Wayang Kulit images.

\section{Research Method}

Black and white images of Wayang Kulit are used as data for this analysis. The Wayang Kulit images were acquired by downloading each shadow puppet one at a time from the Google image search engine using the image format Joint Photographic Group (JPG). Thus, a total of 100 images was download, which was then divided into two categories. There are 50 images classified as protagonists, and the rest were categorized as the antagonist. No identical images were classified in this data collection phase. In the data preprocessing stage, images were manually categorized by a dalang (puppeteer), assuming that a protagonist is facing left while the antagonist is facing right. The images were divided into train data and test data during this phase. Figure 1 shows the example protagonist Wayang Kulit, labeled with numbers 1 to 50. Figure 2 presents the example of an antagonist with numbers 51-100.

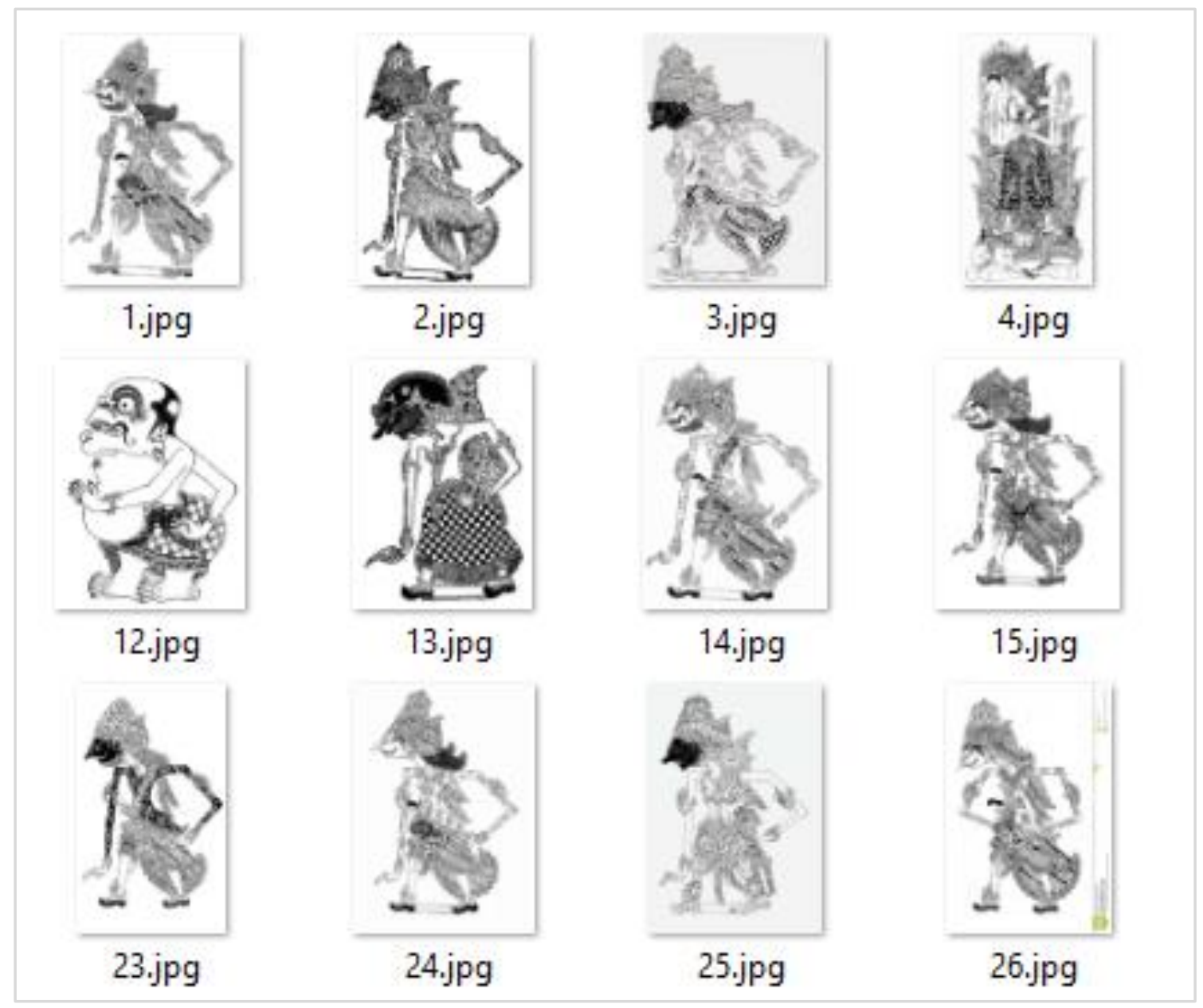

Fig. 1. Example of Protagonist Characters 


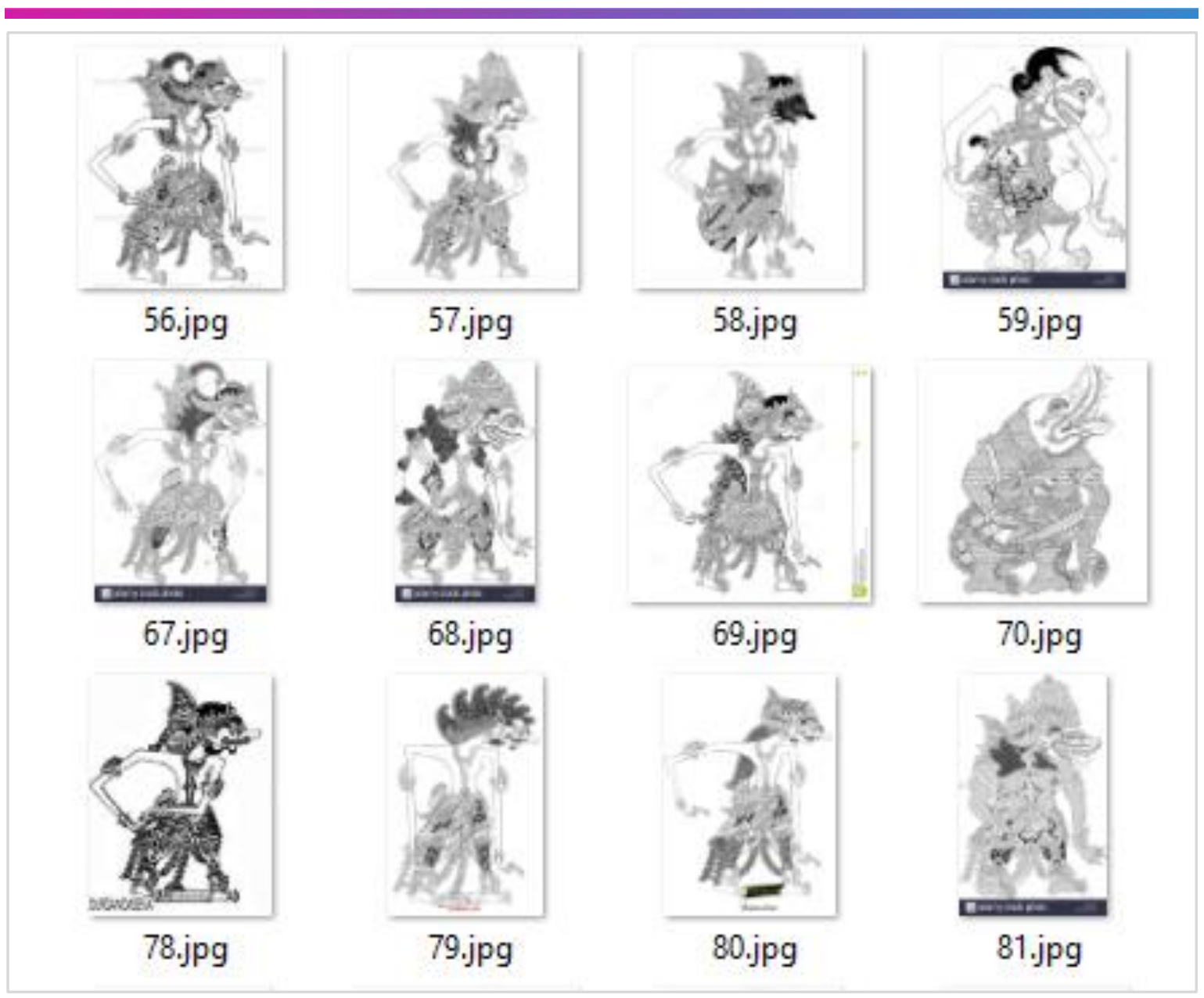

Fig. 2. Example of Antagonist Characters

The scenarios are separated after the Wayang Kulit images have been categorized according to their characters. The purpose of the scenario distribution was to equally determine the CNN method's classification level in recognizing an image object, particularly a Wayang Kulit image. In this analysis, 50 shadow puppet pictures were divided into two groups of 25 images each. The protagonist, Wayang Kulit groups, were considered A1 and A2, whereas the antagonist Wayang Kulit groups were considered B1 and B2. Several preparations and assessment scenarios would be carried out as detailed in Table 1 . The data of the $1^{\text {st }}$ and $3^{\text {rd }}$ scenarios is exactly the same, yet different in scanning the object. The first scenario scans the whole image while the $3^{\text {rd }}$ only the head of Wayang Kulit image.

Table 1. Scenario Categorization

\begin{tabular}{ccc}
\hline Scenario & Testing & Training \\
\hline S1 & A1B1 & A2B2 \\
\hline S2 & A2B2 & A1B1 \\
\hline S3 & A1B1 & A2B2 \\
\hline S4 & A2B2 & A1B1
\end{tabular}

Figure 3 is a system architecture consisting of several stages: image for detection, neuron input, convolution $+\mathrm{ReLu}+$ pooling, fully connected layer, and classification. The first stage, image for detection, equates the image size (resize) with 640x640 pixels using RGB (Red, Green, Blue) with three kernel filters. The result is that the input neurons in the first layer are 1,228,800 neurons (640x640x3). Each neuron has a parameter with a value from 0 to 1. 


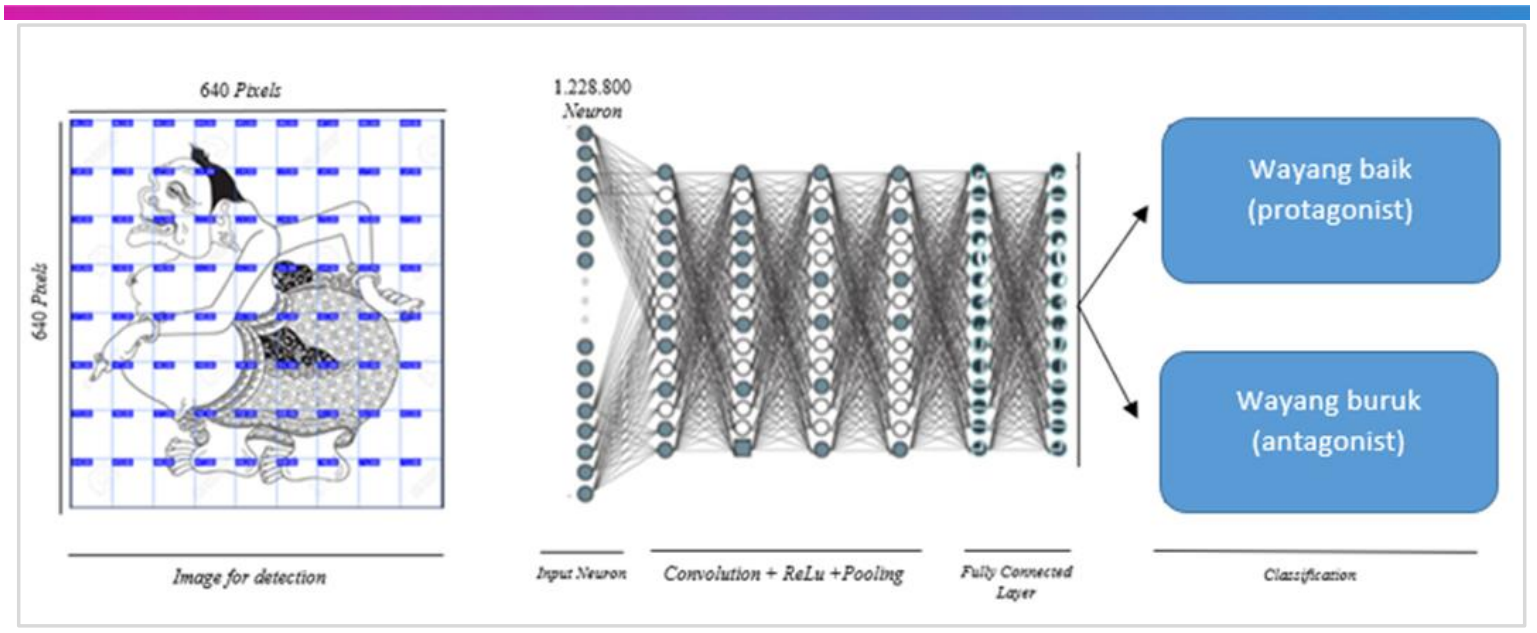

Fig. 3. Developed System Architecture

The next stage is the convolution process. The purpose of the convolution process is to extract the input image. The Convolution Layer comprises several neurons that form a filter in a matrix with length and height (pixels). There are two matrices in the filtering process, namely the input matrix and the kernel matrix. The input matrix value is obtained from the color level of each pixel. At the same time, the value of the kernel matrix is set according to the researcher's needs. The ReLu activation process coincides with the convolution process. ReLu activation aims to determine the output of convolution multiplication. The stage after the convolution and ReLu process is pooling. This pooling process aims to get a new, smaller matrix output. The pooling process carried out in this research is by multiplying the $5 \times 5$ matrix pooling layer with a $3 \times 3$ filter with stride 1 , which produces max pooling with a $3 \times 3$ matrix size. These processes are often carried out to get the desired output matrix before proceeding to the fully connected layer process. The fully connected layer process connects all the results of the neurons in the previous process to the next layer of neurons so that images can be classified. The confusion matrix approach was used to test the classification results [20]. The Confusion Matrix is a table that demonstrates how effective an algorithm's output results are. For example, the character of Wayang Kulit is determined by image classification, which divides Wayang Kulit into two categories: protagonist and antagonist. Table 2 shows the confusion matrix, which is used for performance analysis.

Table 2. Confusion Matrix

\begin{tabular}{llccc}
\hline \multicolumn{3}{c}{ Scenario } \\
\hline \multirow{3}{*}{ Actual } & \multicolumn{3}{c}{ Prediction } \\
\hline & Class & Protagonist & Antagonist \\
\cline { 2 - 4 } & Protagonist & TP & FN \\
\cline { 2 - 4 } & Antagonist & FP & TN \\
\hline
\end{tabular}

True Positive (TP) data is a correct classification based on positive information. True Negative (TN) data correct information based on negative information. False Positive (FP) generates less accurate classification results than positive data. False Negative (FN) is incorrectly classifying the data. These matrices are used to calculate the accuracy, precision, recall, and F-measure as in the following equations.

$$
\begin{aligned}
& \text { Accuracy }=\frac{(T P+T N)}{(T P+T N+F P+F N)} \times 100 \% \\
& \text { Precision }=\frac{T P}{(T P+F P)} \times 100 \% \\
& \text { Recall }=\frac{T P}{(T P+F N)} \times 100 \% \\
& \text { Fmeasure }=\frac{2 x(\text { Precision } x \text { Recall })}{(\text { Precission+Recall })} \times 100 \%
\end{aligned}
$$




\section{Results and Discussion}

Table 3 shows the four scenarios of image classification results. We set the maximum value of iteration in all scenarios to 25000 . The average loss value obtained in all cases was 0.523 . Thus, a value of $700 \mathrm{sec}$ is obtained for Scenario 1. Similarly, using Scenerio2, Scenario 3, and Scenario 4, a value of $800 \mathrm{sec}, 800 \mathrm{sec}$, and $800 \mathrm{sec}$ respectively is obtained.

Table 3. Classification Detection Results

\begin{tabular}{ccccc}
\hline & Scenario 1 & Scenario 2 & Scenario 3 & Scenario 4 \\
\hline Loss & 0,52 & 0,519 & 0,526 & 0,528 \\
\hline Iteration & 25000 & 25000 & 25000 & 25000 \\
\hline Time & $700 \mathrm{sec}$ & $800 \mathrm{sec}$ & $800 \mathrm{sec}$ & $800 \mathrm{sec}$ \\
\hline Classification & $99 \%$ & $99 \%$ & $100 \%$ & $100 \%$ \\
\hline
\end{tabular}

Eventually, the overall rating for all cases receives a score of 99.5 percent. It means that $\mathrm{CNN}$ can differentiate protagonist (Wayang Baik) and antagonist (Wayang Buruk). Figure 4 shows the example of the image detection result. Both scenarios show that CNN recognizes the picture as $100 \%$ good character, even though the scanned part is different.

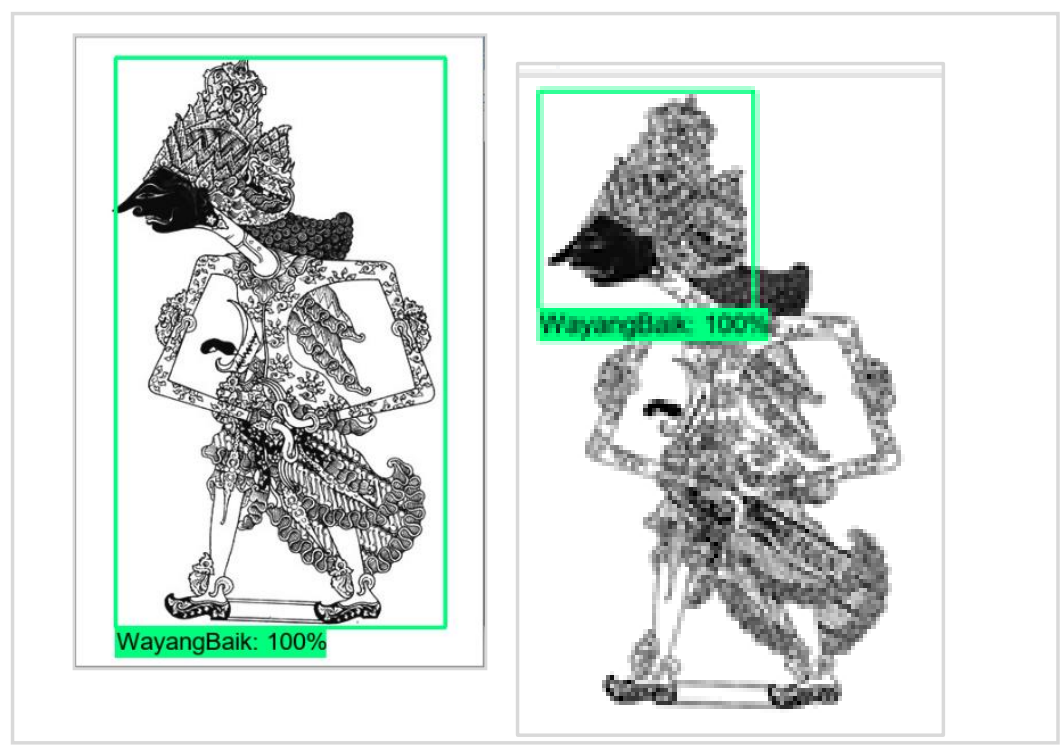

Fig. 4. Detection of Protagonist in Scenario 1 (left) and Scenario 3 (right)

The CNN performance is measured using accuracy, precision, recall, and F-Measure results. Figure 5 shows the CNN accuracy. Red, yellow, green, and blue shows the order of scenario: S1, S2, S3, and S4.

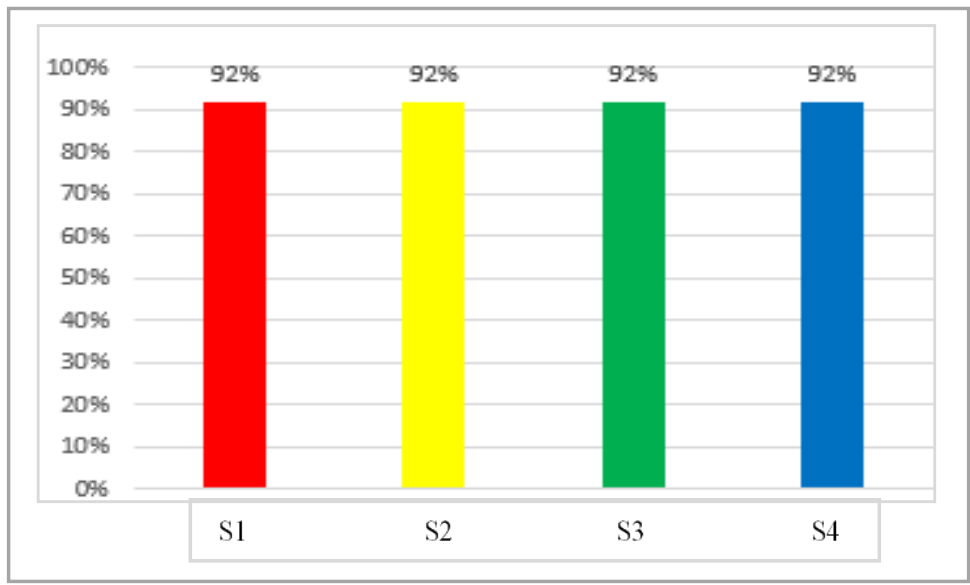

Fig. 5. All Scenarios’ Accuracy 
Figure 5 shows that all of the scenarios earned a 92 percent average score. This accuracy value is used to assess how accurate the classification results are when compared to the real values. However, there is no difference in accuracy between full image detection and head-only detection. Thus measuring with other indicators is needed for better justification.

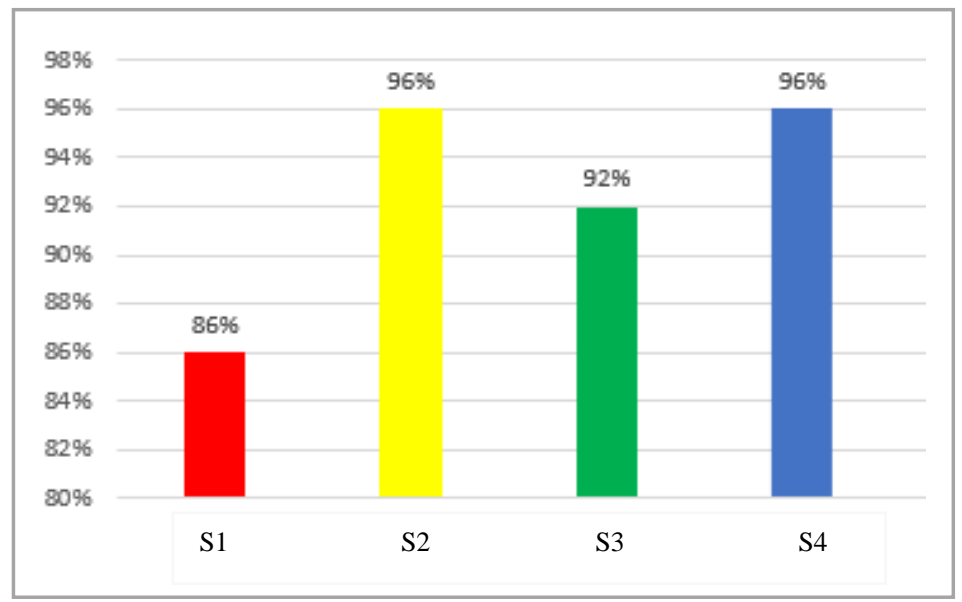

Fig. 6. All Scenarios' Precision

According to Figure 6, Scenario 2 and Scenario 4 offer precision values of 96 percent, 92, respectively. Scenario 3 has a precision value of 92 percent, and Scenario 1 has the lowest precision value of 86 percent. The average precision for the entire scenario was 92.5 percent. The precision value is used to assess the system's accuracy in predicting positive data as opposed to the overall positive forecast performance.

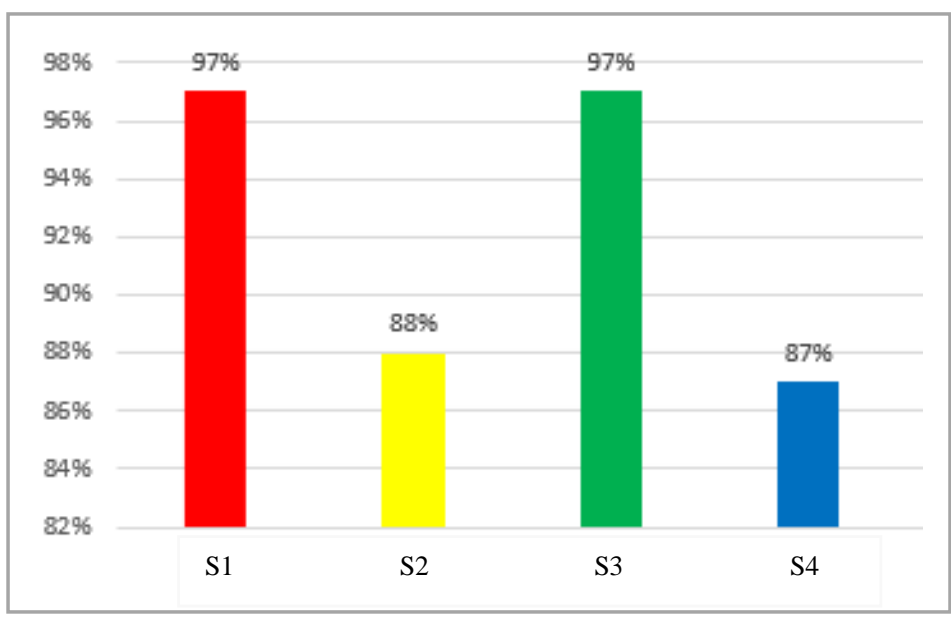

Fig. 7. All Scenarios' Recall

From Figure 7, it can be seen that the recall value in this analysis, the maximum value is obtained in scenarios 1 and 3 with a recall value of 97 percent, followed by Scenario 2 with an 88 percent recall value, and respectively Scenario 4 with an 87 percent recall value. The overall recall value was found to be 92.25 percent. The recall value is used to assess the system's degree of accuracy in predicting true positive data from overall data. 


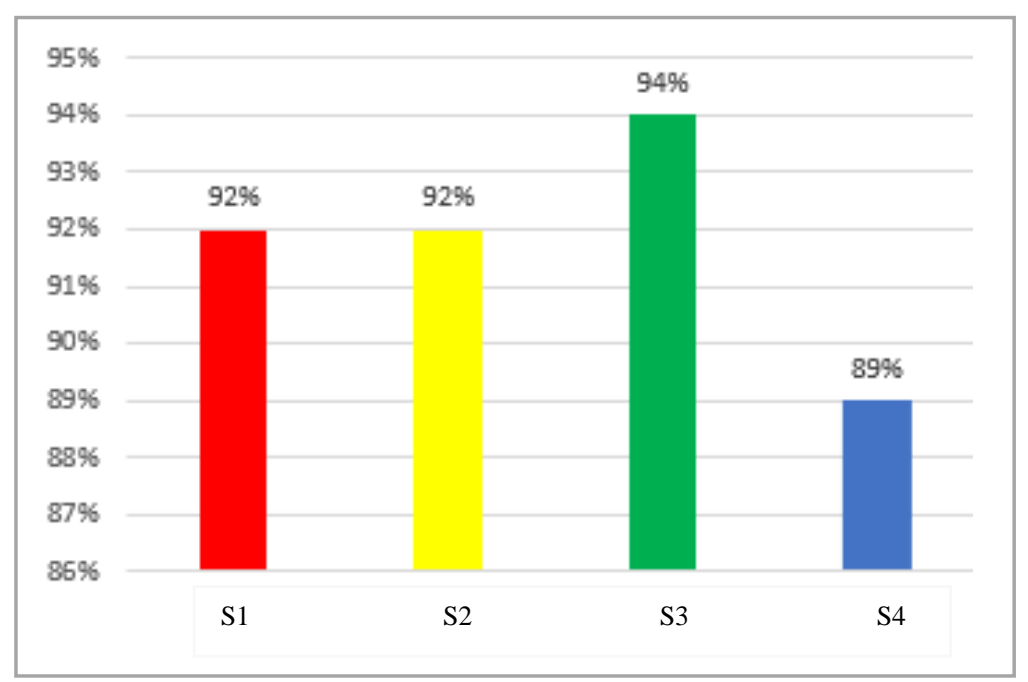

Fig. 8. All Scenarios' F-Measure

Accordingly, Figure 8 presents the maximum value is obtained in Scenario 3 with an F-Measure value of 94 percent, followed by Scenario 1 and Scenario 2 with an F-Measure value of 92 percent, and finally Scenario 4 with an F-Measure value of 88 percent, according to Figure 10, the results of the F-Measure value in this analysis. The average F-Measure value of 91.75 percent was obtained. The F-Measure value is calculated by multiplying the precision and recall values together.

\section{Conclusion}

The system succeeded in classifying Wayang Kulit characters using the Convolutional Neural Network method with the output of protagonist and antagonist characters. In all scenarios, the level of accuracy for the classification of Wayang Kulit characters using the Convolutional Neural Network method obtained an average value of 92 percent. Precision was given an average score of 92.5 percent. The recall value was found to be 92.25 percent on average. The average value of the F-Measure value was 91.75 percent. In the future, we may increase the number and resolution of images that are more diverse to train the model and acquire a higher classification value. Another future classification is wayang's name instead of its character. This development may help teenagers to know their culture better.

\section{References}

[1] M. Ilhamullah and M. Rachmawati, "Kesinambungan pada Galeri Kesenian Wayang Kulit Jawa Timur," J. Sains dan Seni ITS, vol. 3, no. 2, pp. G42-G45, 2014. doi: 10.12962/j23373520.v3i2.6546

[2] P. Priyanto, "Menggali Nilai-Nilai Kepemimpinan Budi Luhur Dalam Pertunjukkan Wayang," J. Nas. Teknol. Terap. Berbas. Kearifan Lokal, pp. 447-452, 2019. Available at: Google Scholar

[3] S. Subiyantoro and S. S. Fadhilah, "A Study on Teachers' Perceptions towards Cultural Arts Subject Using Wayang Kulit Purwa to Students of Junior High School in Solo Raya," Int. J. Pedagog. Teach. Educ., vol. 4, no. 2, p. 138, Dec. 2020. doi: 10.20961/ijpte.v4i2.44145

[4] Y. L. Pramono, S. Suyanto, and A. Wahida, "Shadow Puppet Arts as The Formation of Young Generation Character," in Proceeding of International Conference on Art, Language, and Culture, 2017, pp. 397404. Available at: Google Scholar

[5] M. I. Cohen, "Wayang in Jaman Now : Reflexive Traditionalization and Local, National and Global Networks of Javanese Shadow Puppet Theatre,” Theatr. Res. Int., vol. 44, no. 1, pp. 40-57, Mar. 2019. doi: $10.1017 / \mathrm{S} 0307883318000834$

[6] Y. L. Pramono and A. W. Suyanto, "Learning for Making Wayang Kulit in Sanggar Asta Kenya Art," Int. J. Adv. Multidiscip. Sci. Res. ISSN 2581-4281, 2 (2), February, 2019, \# Art, vol. 1211, pp. 1-12, 2019. doi: 10.31426/ijamsr.2019.2.2.1211 
[7] A. Ahmadi, "The Creativity of Wayang Kulit (Shadow Puppet) Crafts in Surakarta," Arts Des. Stud., vol. 58, pp. 41-51, 2017. Available at: core.ac.uk

[8] M. E. Varela, "Wayang Hip Hop: Java's Oldest Performance Tradition Meets Global Youth Culture," Asian Theatr. J., vol. 31, no. 2, pp. 481-504, 2014. doi: 10.1353/atj.2014.0049

[9] M. Downes, "Hybridities and Deep Histories in Indonesian Wayang Manga Comics," Situations, vol. 8, no. 2, p. 5, 2015. Available at: Google Scholar

[10] A. Kurnianto and F. Limano, "Visual representation of character of wayang kulit purwa in the wayangbased games: Case studies of Kurusetra and Mahabarat warrior games," in 2016 1st International Conference on Game, Game Art, and Gamification (ICGGAG), 2016, pp. 1-6. doi: 10.1109/ICGGAG.2016.8052666

[11] N. Bonafix, "Designing Wayang Kulit Purwa with Gatotkaca as the Character in Game," J. Games, Game Art, Gamification, vol. 2, no. 1, 2017. Available at: Google Scholar

[12] D. A. Ghani, "Wayang kulit: Digital puppetry character rigging using Maya MEL language," in 2011 Fourth International Conference on Modeling, Simulation and Applied Optimization, 2011, pp. 1-5. doi: 10.1109/ICMSAO.2011.5775499

[13] M. H. Tsai and A. T. E. Hapsari, "Usage Of 12 Animation Principles In The Wayang Kulit Performances," J. Telemat., vol. 6, no. 1, 2010. Available at: Google Scholar

[14] A. Ardiyan and D. Syamsuddin, "Aesthetic Affordances of Buto's Shape and Texture Characters in Wayang Kulit Through Digital Sculpting," in 2019 International Conference on Sustainable Engineering and Creative Computing (ICSECC), 2019, pp. 380-385. doi: 10.1109/ICSECC.2019.8907061

[15] R. Jose, "A Convolutional Neural Network (CNN) Approach to detect face using Tensorflow and Keras," J. Emerg. Technol. Innov. Res., vol. 6, no. 5, pp. 97-103, 2019. Available at: Google Scholar

[16] P. Kamencay, M. Benco, T. Mizdos, and R. Radil, "A new method for face recognition using convolutional neural network," Adv. Electr. Electron. Eng., vol. 15, no. 4 Special Issue, pp. 663-672, 2017. doi: $10.15598 /$ aeee.v15i4.2389

[17] M. Nimbarte and K. Bhoyar, "Age invariant face recognition using convolutional neural network," Int. J. Electr. Comput. Eng., vol. 8, no. 4, pp. 2126-2138, Aug. 2018. doi: 10.11591/ijece.v8i4.pp2126-2138

[18] Q.-Q. Tao, S. Zhan, X.-H. Li, and T. Kurihara, "Robust face detection using local CNN and SVM based on kernel combination," Neurocomputing, vol. 211, pp. 98-105, Oct. 2016. doi: 10.1016/j.neucom.2015.10.139

[19] J. Tan et al., "GLCM-CNN: Gray Level Co-occurrence Matrix based CNN Model for Polyp Diagnosis," in 2019 IEEE EMBS International Conference on Biomedical \& Health Informatics (BHI), 2019, pp. 14. doi: 10.1109/BHI.2019.8834585

[20] A. P. Wibawa, H. K. Fithri, I. A. E. Zaeni, and A. Nafalski, "Generating Javanese Stopwords List using K-means Clustering Algorithm," Knowl. Eng. Data Sci., vol. 3, no. 2, p. 106, Dec. 2020. doi: 10.17977/um018v3i22020p106-111 